\title{
CONTROL PARLAMENTARIO Y COMISIONES INVESTIGADORAS (Parlamento ante la Reforma Constitucional)
}

\author{
FRANCISCO ZÚÑIGA URBINA \\ Profesor Universidad de Chile, Universidad Central \\ y Universidad La República
}




\section{•}




\title{
CONTROL PARLAMENTARIO Y COMISIONES INVESTIGADORAS (Parlamento ante la Reforma Constitucional)
}

\author{
POR \\ FRANCISCO ZÚÑIGA URBINA \\ Profesor Universidad de Chile, Universidad Central \\ y Universidad La República
}

I. DEMOCRACIA Y AUTOCRACIA: DECLINACIÓN DEL PARLAMENTO

Los esquemas bipartitos que descansaban en elementos cuantitativos (titulares del poder) y cualitativos (virtud-fin) del poder como el clásico enfoque de Aristóteles o el sincrético enfoque de Polibio; son superados en la modernidad por la bipartición entre Repúblicas y Monarquías planteada por Maquiavelo.

Tal bipartición maquiaveliana es reformulada por autores contemporáneos como categoría: formas de Estado como genus frente a sus concreciones institucionales, las formas de Gobierno. Así a partir de la moderna bipartición entre democracia y autocracia, utilizaré los planteamientos de Schmitt y Kelsen para definir el lugar del Parlamento en la organización del Estado democrático.

A propósito del Estado de partidos ${ }^{1}$ en el rico microcosmos cultural de Weimar precisamente se planteaban contrapuestas concepcio-

1 Sobre "formas de gobierno" un texto obligado de consulta de Norberto Bоввı "Teoría de las formas de Gobierno en la historia del pensamiento político", F.C.E., México D.F., 1989, págs. 33-56-64-79. 
nes del mundo (absolutismo-relativismo), en que el resultado fue, bajo el pretexto de criticar la democracia parlamentaria, justificar la instauración de regímenes autocráticos de diversa impronta ideológica.

La disputa teórico-práctica Schmitt-Kelsen, Adler-Kelsen, son reflejo de una fructífera discusión para la teoría democrática y constitucional. Los "años turbulentos» de entreguerra (Mirkine Guetzévitch) de revolución política-social en Europa, junto con decantar nuevas tendencias constitucionales; permitió sentar la base de una reelaboración de la teoría del Estado y de la Constitución fundada precisamente en el principio democrático ${ }^{2}$. Con todo, vale la pena reseñar sintéticamente las posiciones teóricas de Schmitt y Kelsen.

En 1923 C. Schmitt publica una monografia: "Situación Histórico-Intelectual del Parlamentarismo de Hoy" ${ }^{3}$, que es una fina construcción teórica, desde supuestos ideológicos conservadores autocráticos, que transmuta la emergente crisis de la República parlamentaria de Weimar en la crisis del parlamentarismo, de la democracia y del Parlamento; "trampa ideológica" a la que Schmitt nos tiene acostumbrado. En Italia Pareto y Mosca, en España J. Costa y F. J. Conde, en Chile G. Izquierdo A. y A. Edwards, incurren en análogas trampas ideológicas Para Schmitt en la raíz del parlamentarismo está la relación fiduciaria (confianza-responsabilidad) del Gobierno ante el Parlamento, es una "comisión del pueblo y el gobierno una comisión del Parlamento". La ratio del Parlamento es lo "dinámico-dialéctico", es decir, "un proceso de controversias entre contradicciones y opiniones, de lo que resultaría la auténtica voluntad estatalı, su esencia es el debate, la deliberación de argumento y contraargumento: para que las upartículas de razón" se conviertan en poder político. En este contexto la afirmación del principio de publicidad de los actos del poder es un reflejo de la repulsa de los arcana imperii, y de una condición para formar opinión pública. A la fe en el principio de publicidad se agrega el principio de "separación de poderes" conducente al equilibrio pluralista de poder. Este marco de principios, fundado ideológicamente en concepciones meca-

Garcia Pelayo, Manuel: «El Estado de Partidos». En "Obras Completas» (3 vol.), Vol. H, págs. 1969-2078.

También consultar a A. TORRES DEL MORAL: «Estado de Derecho y Democracia de Partidos», U.C., Madrid, 1991.

2 Mirkine GuetzévitCH, Boris: "Las Nuevas Constituciones del Mundo" (Estudio Preliminar), Editorial España, Madrid, 1931, págs. 7-57.

3 Scнmiтt, Carl: "Sobre el parlamentarismo", Edit. Tecnos, S.A., Madrid, 1990, págs. 3-97. 
nicistas-naturalistas como observa Schmitt, se configura en "Estado Legislativo", en que el Parlamento tiene una función prevalente: la función legislativa. Pero para Schmitt publicidad y discusión son conceptos obsoletos, ante el influjo decisivo de los partidos y oligarquías, campo en que el argumento de la autoridad de R. Michels es contundente en apariencia.

Para Schmitt el parlamentarismo es una "mala fachada del dominio de los partidos y de los intereses económicos", y en el Prefacio de 1926 llega a afirmar que "la fe en el parlamentarismo, en un government by discusión", es propia de las ideas del liberalismo. No es propia de la "democracia", con lo cual «bolchevismo y fascismo" son antiliberales, "pero no necesariamente antidemocráticos". En suma, en una democracia "vital» el Parlamento es una "maquinaria artificial». Con mayor rigor en 1928 Schmitt en su "Teoría de la Constitución" ${ }^{4}$ reitera que en el Parlamento del Estado burgués de Derecho está el lugar "en donde se realiza la discusión pública de las opiniones políticas». En lo "dinámico dialéctico" el Parlamento encuentra una "verdad razonable y la norma justa”.

Las consecuencias de esta concepción del parlamentarismo son: "1. El Parlamento representa a toda la nación como tal y emite por ello, en discusión y acuerdos públicos, leyes, es decir, normas generales, justas que determinan y regulan toda la vida estatal" (...) "2. El diputado concreto tiene, asimismo, carácter representativo». Para Schmitt estos "supuestos ideales" del parlamentarismo desaparecen en la democracia "actual»:

a) “Desaparece la discusión. El Parlamento, en la mayor parte de los Estados, no es hoy un lugar de controversia racional donde existe la posibilidad de que una parte de los diputados convenza a la otra y el acuerdo de la Asamblea publica en pleno sea el resultado del debate ...".

b) "Desaparece la publicidad. La Asamblea pública en pleno no es ya el lugar en que, a base de discusión, pública, surge la decisión ...".

c) "Desaparece el carácter representativo del Parlamento y del diputado. Por lo tanto, el Parlamento no es ya el lugar en que recae la decisión política ...".

Schmitt con posterioridad a propósito del art. 48 de la Constitución de 1919 transformará el Presidente del Reich en custodio de la

4 Sснміт, C.: "Teoría de la Constitución" (trad. F. Ayala), Alianza Editorial, S.A., Madrid, 1982, págs. 304-305-306-307. 
Constitución, y, más tarde al Canciller del Reich, quien es soberano, pues decide el caso excepcional.

Con todo, Schmitt y buena parte de los juristas autocrático-conservadores germanos de la era Weimar encuentran la crítica y respuesta implacable de Kelsen. En 1920 (1929) en su opúsculo "Esencia y Valor de la Democracia" Kelsen ${ }^{5}$ aborda en profundidad el concepto de democracia y su articulación estatal jundico-política el parlamentarismo; temas recurrentes en su prolífica obra y longeva vida. Para el maestro vienés el parlamentarismo significa "formación de la voluntad decisiva del Estado mediante un órgano colegiado elegido por el pueblo en virtud de un derecho de sufragio general e igual, o sea democrático, obrando a base del principio de la mayoría». Kelsen reconoce en la representación política una ficción para imputar efectos y decisión del pueblo en el Parlamento, pues tal ficción permite comprender la participación en la formación de la voluntad estatal por el pueblo, lo que guarda congruencia con la división del trabajo que expresada en la separación de poderes expresa una creciente "racionalización del poder". En 1925 Kelsen en la monografía "El Problema del Parlamentarismon ${ }^{6}$ reitera con fuerza su argumentación, y se hace cargo de la critica de Schmitt al proceso "dialéctico-contradictorio" propio del Parlamento y de filiación liberal, crítica que arrastra una visión metafísico absolutista; de suerte que el elemento "dialógico" es resultado de una aproximación "crítico relativista" propia de la democracia. El maestro vienés en su magnifica "Teoría General del Estado" (1925) incorpora al elemento "dialéctico-contradictorio" la necesidad del "compromiso políticon, sobre la regla de mayoría-minoría y sobre un ethos específico: el caro valor de la tolerancia?.

Ciertamente la "trampa ideológica" de Schmitt es fina, tentadora, pero falaz, hemos dicho transmuta la crisis del parlamentarismo "racionalizado" de Weimar en la crisis del parlamentarismo como forma de Gobierno de la democracia, como forma de Estado y en particular del Parlamento como institución. La crítica al Parlamento es la crítica a la ficción de la representación política, a los partidos políticos, y a la ley como expresión de la voluntad general. Esta crítica descansa

5 Kelsen, Hans: "Esencia Valor de la Democracia» (trad. R. Luengo T. y L. Legaz), Edit. Labor, S.A., Barcelona, $2^{2}$ ed., 1977, pág. 50.

6 KelSeN, H: «El problema del Parlamentarismo». En Escritos sobre "la Democracia y el Socialismo", Edit. Debate, S.A:, Madrid, 1985, págs. 85-108.

7 Kelsen, H: "Teoría General del Estado» (trad. L. Legaz), Edit. Nacional, México, 1965, págs. 453-473. 
en supuestos ideales del parlamentarismo y del Parlamento que nunca existieron en la realidad del proceso político del siglo XIX, en particular en las monarquías constitucionales.

A modo de conclusión metódica en este punto, la referencia al debate Schmitt-Kelsen es un pretexto, para desvelar las visiones demonizadoras de la democracia representativa y, del Estado de partidos, visiones que en la Dogmática Constitucional son profundamente ideológicas. La centralidad del Parlamento en la actualidad, en particular en regímenes presidencialistas exige un tratamiento riguroso del tipo de reparto de poder y de controles inter-órganos, para que tal centralidad redunde en un perfeccionamiento de la democracia y no en una categoría postiza inadecuada para nuestro régimen político y tipo de gobierno.

\section{PRESIDENCIALISMO Y PARLAMENTO}

Antes de recoger una definición del presidencialismo cabe definir los conceptos de forma del Estado y de Gobierno, y del molde clásico: el "régimen presidencial». Con G. De Vergottini por "forma del Estado" entendemos "el conjunto de elementos que caracterizan globalmente, a un ordenamiento referido particularmente a finalidades planteadas como objetivos de acción de los órganos constitucionales" $y$ por "forma de Gobierno" entendemos "el complejo de instrumentos que se articulan para conseguir finalidades estatales y por lo tanto, los elementos que miran a la titularidad y ejercicio de las funciones soberanas atribuidas a los órganos constitucionales»" En cuanto al «régimen presidencial» (tal denominación fue usada por W. Bagehot en "The English Constitution"), designa el tipo de Gobierno (y régimen político) de Estados Unidos en que la Presidencia rocupa un lugar vital y básico entre las instituciones públicas a nível nacional" (R. E. Neustadt), en que el poder presidencial es un "poder de persuadir", no obstante su diversidad de "poderes formales".

El «régimen presidencial» en que el Presidente "reina y gobierna a la vez" es un producto de la Constitución de 1787, de los precedente y de la práctica moderna; siendo las "ventajas" de este la siguientes: "La primera es la seguridad de su inamovilidad durante un período de cuatro, años, sólo amenazada por un voto de acusación (impeachment)

8 VergottinI, Giuseppe De: "Derecho Constitucional Comparado" (trad. P. Lucas Verdú), Espasa Calpe, S.A., Madrid, 1985, págs. 107-108. 
del Congreso, procedimiento incómodo que sólo se intento (hasta la destitución de Nixon) una vez en 1867. La segunda, la elección popular indirecta por medio de un colegio electoral. La tercera, la jefatura de las fuerzas armadas y la dirección de la diplomacia, prerrogativas tradicionalmente reales, concedidas a la presidencia por los antiguos súbditos británicos. La cuarta, una serie de derechos y deberes específicos relativos a la dirección de la Administración Pública, el más importante de los cuales es el derecho de nombrar jefes de Departamento y el deber de "cuidar de que las leyes sean fielmente cumplidas". La quinta, una prerrogativa limitada sobre la legislación: el poder del veto cualificado y el derecho de recomendación (...). "Pero la Constitución, que establecía las bases de la presidencia, establecía como principio básico el que sus privilegios estuviesen contrarrestados por los de otras instituciones nacionales, $y$ en especial el Congreso" (separación de poderes). "La Constitución garantizaba a una o más cámaras la participación en todas las vertientes del poder presidencial. El mando de la defensa estaba limitada por el hecho de que los contingentes y los fondos de la fuerzas armadas, dependian de la decisión del Congreso, que se reservaba el derecho de declarar la guerra. El mando de la diplomacia estaba limitada por el hecho de que el Senado se reservaba el derecho de su "poder y aprobación" a los tratados. El mando de la administración estaba severamente limitado por el hecho de que la moneda, la autoridad y la estructura departamental estaban sujetas a una legislación específica y las personas nombradas por el presidente sometidas a la confirmación del Senado. En materia legislativa, el Congreso era la instancia suprema, limitada únicamente por el veto presidencial, que, a su vez, estaba sujeto al voto en contra de los tercios de las dos Cámaras"'. En suma, el "régimen presidencial» descansa en un principio-dogma de "separación rigida» de poderes (Duverger), combinación de «democracia y poder personal» con un sistema "bipartidista».

El "régimen presidencial" de América del Norte encuentra en América Catina su copia superlativa: el presidencialismo caracterizado

9 Neustadt, Richard E.: "Presidencialismo" de Enciclopedia de Ciencias Sociales, Edit. Aguilar, S.A., Madrid, 1977, págs. 442-447. Idem: “El Poder Presidencial" (trad. E. Escalona), Edit. Limusa-Wiley, S.A., México D.F., 1966.

Idem Manuel Garcia Pelayo para una visión general del ordenamiento constitucional de Estados Unidos de América "Derecho Constitucional Comparado" Alianza Editorial, S.A., Madrid, 1984, págs. 325-455 (también Obras Completas, vol. I), C.E.C., Madrid, 1992. También de consulta obligada es L. H. TRIBE: «American Constitucional Law" (2 edic.), The Foundation Press, Inc., Mineola-New York, 1988, en especial págs. 1-339. 
por la preponderancia o predominio del Ejecutivo (Lambert). La exaltación del "poder personal" es producto de una continuidad histórica; en palabras de Duverger: "al cacique indio sucedio el conquistador español; el Virrey, encarnaba, él solo, la totalidad del podern ${ }^{10}$. El presidencialismo cuenta con análogas instituciones que los Estados Unidos, pero el Presidente consigue una preponderancia hegemónica. Con agudeza Jacques Lambert en su clásico libro "América Latina» observa que: "el vicio inherente al régimen de preponderancia presidencialista en la América Latina, no es, como se afirma con frecuencia, su aptitud para engendrar dictaduras puesto que éstas se producen del mismo modo, y quizás con mayor facilidad, con otros regímenes, sino la de prestarse a disimular las dictaduras bajo formas constitucionales, hasta tal punto que, el dictador, que puede conservar su buena conciencia, no se ve obligado a violarlas abiertamente (...)". La garantía de la democracia en este tipo de régimen se encuentra en el carácter temporal del mandato presidencial. Así "como puede advertirse que los constituyentes latinoamericanos se esfuerzan mucho menos en limitar los poderes del Presidente, cuya extensión consideran que no carece de ventajas, que por asegurarse el carácter temporal, multiplicando las precauciones contra las tentativas del Presidente de perpetuarse en el poder, asegurando su reelección o la de algunos de sus testaferros (continuismo) "11.

Ciertamente la concentración de poder público en la institución presidencial ha tenido como consecuencia la anulación o menoscabo de la democracia pluralista y de las libertades públicas. La preponderancia se ejerce a través de factores institucionales o funcionales (A. Lago Carballo); a saber: a) iniciativa legislativa del Presidente de la República; b) el veto presidencial suspensivo y parcial), c) facultades legislativas del Presidente en especial el instituto de la delegación de facultades legislativas; d) intervención federal, que correspondiendo por regla al Parlamento, es el Presidente quien toma la iniciativa de su disposición; e) facultades extraordinarias, tanto en el campo del estado de necesidad constitucional como la "emergencia económica", que conlleva la existencia de poderes de excepción y f) un poder judicial su-

10 Duverger, Maurice: "Los Regímenes Políticos» (trad. Z. de Godoy), Salvat Editores, S.A., Barcelona, 1952, pág. 114.

11 LAMBert, Jacques: "América Latina» (trad. A. Lago C.), Edit. Ariel, S.A., Barcelona, 1964, 2 ed., 1970, pág. 516-517.

La cita de $A$. Lago Carballo esta referida a apéndice de texto de $M$. Duverger "Instituciones Políticas y Derecho Constitucional», Edit. Ariel, S.A., Barcelona, 1988, págs. 591 y ss. 
bordinado ante la ingerencia del Poder Ejecutivo. Para corregir el predominio presidencial se han introducido umecanismos anticaudillistas" (Valencia) ${ }^{12}$ : restricción del mandato presidencial fijo sin reeleción (con su paragidma mexicano peligrosamente suprimido en Perú y Argentina), descripción de sus facultades o atribuciones, incorporación de matices parlamentarios como el mayor control político, colegiación del Gobierno, refrendo, etc. (Colomer). Sin embargo, los elementos institucionales del presidencialismo en América Latina no autorizan a hablar de un tipo homógeneo (Colomer, Carpizo, Sánchez Agesta) ${ }^{13}$.

Me parece en este punto especialmente sugestiva la tipología propuesta por el americanista valenciano A. Colomer Viadel, quien de manera sincrética combina de una parte la relación interna de competencias constitucionales y comportamientos institucionales y de otra, la relación externa de la Presidencia con otros poderes y el conjunto social, a saber:

1. PRESIDENCIALISMO HEGEMÓNICO DE EXCEPCIÓN. «En este caso se produce una invasión de las esferas de competencias de los otros poderes, por el Ejecutivo -de una manera temporal-o existe la posibilidad permanente de recurrir a procedimientos para atribuirse, de nuevo, competencias en numerosas materias especialmente, las relacionadas con la libertad y la seguridad pública Asimismo, existe una mediatización del Ejecutivo presidencial en los nombramientos y elección de miembros, de los otros poderes" (...) "La consecuencia constitucional es la hegemonia permanente de una parte -la Presidencia ejecutiva sobre el conjunto del sistema poderes y libertades de la Constitución. Esta categoría de presidencialismo puede darse con gobiernos militares o civiles, oligárquicos o no, porque lo definitorio es la ubicación y utilización especial de los mecanismos constitucionales que el modelo establece».

12 VALENCIA, Salvador: “EI Poder Ejecutivo Latinoamericano ", UNAM, México D.F., 1979.

13 COLOMER VIADEL, Antonio: "Introducción al Constitucionalismo Iberoamericano", Edit. ICl, Madrid, 1990.

Idem: "Constitución, Estado y Democracia en el Umbral del Siglo XXI", Edit. Nomos, Valencia, 1995, págs. 73 y ss.

SÁnCHEZ Agesta, Luis: "La Democracia en Hispanoamérica", Edic. Rialp, S.A., Madrid, 1987, págs. 53 y ss, 207-236.

Idem: "Curso de Derecho Constitucional Comparado", Edit. U.C., Madrid, $7^{2}$ ed., 1988, págs. 244-255.

CARPIZO, Jorge: "EI Presidencialismo Mexicano», Edit. Siglo XXI Editores S.A., México, 1978.

Idem: «Notas sobre el Presidencialismo Mexicano». En «Estado, Derecho y Sociedad», Edit. Unam, 1981, págs. 69-85. 
2. PRESIDENCIALISMO HEGEMÓNICO CONSTITUCIONAL DEMOCRÁTICO. "En esta segunda categoría la hegemonía presidencial sobre los otros poderes no se realiza por mecanismos de excepción mediante el uso regular de las facultades del Ejecutivo, previstas en la Constitución" (...) "La influencia política de la Presidencia en el reclutamiento de los miembros de los otros poderes es también otro factor de la Presidencia sobre el conjunto del sistema político y constitucional'".

3. PRESIDENCIALISMO AUTÓNOMO DE EQUILIBRIO DE PODERES. "El modelo constitucional de la clásica división de poderes del régimen presidencial, que limita la acción presidencial sobre los restantes poderes, y la restringe especialmente en el campo legislativo".

4. PRESIDENCIALISMO CON SUJECIÓN PARLAMENTARIA. "Esta categoría responde a la simbiosis entre la existencia de un ejecutivo unipersonal, representado por un Presidente de elección popular directa $-y$ no responsable ante el Parlamento- $y$ algunas notas del parlamentarismo" ${ }^{14}$.

En este cuadro cabe preguntarse por la imbricación del Parlamento en el régimen político. El constitucionalismo en América Latina es reflejo de dos modelos: el constitucionalismo de América del Norte que combina división de poderes y régimen presidencial, y el constitucionalismo francés que otorga predominio al Parlamento (Colomer). En los hechos la realidad política refleja una dialéctica Gobierno-Parlamento, que permea el constitucionalismo y la configuración del régimen-tipo gobierno en el cuadro del genus presidencialismo. El caso de Chile con presidencialismos de corte autocrático (1830-1891) y democrático (1925-1973), mediando un período de seudoparlamentarismo (1891-1925) es un botón de muestra de esta dialéctica ${ }^{15}$. Ejemplo de esta dialéctica es la caracterización del presidencialismo americano del Norte en la obra de W. Wilson.

La iuspublicistica y politología cargando las tintas en el factor central del presidencialismo -el predominio del Ejecutivo-, ha prescindido de la dialéctica del Gobierno-Parlamento, haciendo inexplicables las tendencias vigorizadoras del Ejecutivo, que se manifiestan en diversos paises de nuestra América. En los albores de este siglo fue tópico hablar de "crisis de la democracia" (Mirkine Guetzévitch) o de "declinación del Parlamento" (Bryce), términos que en un proceso de

14 Colomer, V. A.: Ob. cit., págs. 129-130.

15 Amunátegul, J. Gabriel: "Regímenes Políticos", Edit. Jurídica de Chile, Santiago, 1951, págs. 187-232. 
racionalización del poder designaron cambios profundos en la forma del Estado y de Gobierno. Por lo tanto, el "eclipse" del Parlamento es un fenómeno que no se debiera exagerar (Lambert); puesto que frente al "caudillismo" u otras formas de personalismos, existen poderes fácticos: oligarquías o "frondas aristocráticas" como las denominó en Chile A. Edwards Vives. Un botón de muestra es el caso de Chile que en el contexto de una Constitución autoritaria (1980) posee un Parlamento racionalizado que ejerce las funciones tradicionales asignadas a este órgano de representación política, y tiene un claro fin legitimador del sistema político democrático en transición. Con este contexto cabe matizar el predominio o preponderancia del "Poder Ejecutivo", ya que incluso un Congreso Nacional racionalizado, impone al Gobierno una dialéctica de negociación; a lo que cabe agregar la supervivencia del régimen autoritario a través de "enclaves" que pugnan con el principio democrático. En este sentido, el plantamiento de Sánchez Agesta en orden a un Parlamento en América Latina con "un funcionamiento anormal" no me parece adecuado, pues son tantas la excepciones a la intermitencia, que esta tesis se ve anulada más aún si reconocemos de esta institución un impulso constituyente, probablemente carente de moderación, pero rico en nuevas ideas.

\section{PARLAMENTO Y FUNCIÓN DE CONTROL}

Las funciones del Parlamento admiten diversas tipologias que dan cuenta de una profunda historicidad. V. gr: las funciones legislativa y financiera asentadas en el aforismo inglés: "no taxation without representation". En el campo de las tipologías el tratadista P. Biscaretti Di Ruffia nos refiere a funciones legislativa, funciones ejecutivas $\left(1 .^{\circ} \mathrm{de}\right.$ control continuado del Gobierno, $2 .^{\circ}$ de colaboración activa en la deliberación de la orientación política y $3 .^{\circ}$ de colaboración en la formación de otros órganos constitucionales) y función jurisdiccional política ${ }^{16}$. Asimismo, el maestro italiano G. De Vergottini rearticula las funciones del Parlamento a partir de su relación con el Gobierno, a saber: función de orientación del Ejecutivo, función de orientación y control del Parlamento, función cognoscitiva e inspectiva del Parlamento, función legislativa del Parlamento y función normativa del Gobierno. Finalmente, el maestro Nicolás Pérez Serrano en su enjundioso «Tratado de

16 Biscaretti di Ruffia, Paolo: "Derecho Constitucional" (trad. P. Lucas Verdú), Edit. Tecnos, S.A., Madrid, 1973, págs. 387 y ss. 
Derecho Politicon formula una tradicional taxonomía: función legislativa, función financiera (presupuestaria), función fiscalizadora, función política, función administrativa interna, función de tipo jurisdiccional ${ }^{17}$. Sin duda la reseña corresponde a tipologias asentadas en patrones históricos o en tipos de gobierno concretos.

Centraremos esta ponencia en la función de control $v$ sus medios, a partir de aceptar ciertos tópicos, que con sus debidas matizaciones me parecen acertados, a saber:

1. El fenómeno de la "declinación del Parlamento»18 (J. Bryce) observado a principios de siglo en la doctrina iuspublicística se enmarca en el proceso de "racionalización del poder" (Mirkine Guetzévitch), que con independencia del régimen político-tipo de Gobierno, se traduce en la asignación de facultades legislativas al Poder Ejecutivo.

2. El surgimiento de un Estado Administrativo contrapuesto dialécticamente al Estado Legislativo (Schmitt), coincidente con una vigorización del Poder Ejecutivo (Gobierno y Administración).

3. Crisis del concepto material de ley como expresión de la voluntad general que contiene una prescripción general, abstracta y coercible, como garantía del principio de igualdad y derechos de igualdad.

4. La configuración de Presidencia de la República y Parlamento, en especial en regímenes presidencialistas como órganos constitucionales colegisladores que participan en el iter legis con atribuciones de bloqueo recíproco.

5. El especial posicionamiento de la función de controly de sus medios de cognición e inspección está asociado a la plurisignificación y multidimensionalidad del control parlamentario.

En consecuencia, nuestro planteamiento central es que el Parlamento dada las transformaciones en el Estado contemporáneo (Estado Benefactor) en especial en el proceso político del Estado de partidos, requiere para su centralidad identificar los medios apropiados para lograr una eficiente función de control del Gobierno y de la Administración.

17 Pérez Serrano, Nicolás: "Tratado de Derecho Politico", Edit. Civitas, S.A., Madrid, $2^{\mathrm{a}}$ ed. reimp, 1989, págs. 787-818.

18 BRYCE, James: "Modern Democracies", Edit. Mac Millan and Co, London, 1921, 2 vol., vol. II, págs. 367-377. 
Particular importancia tiene esta centralidad del Parlamento en los regímenes presidencialistas, en que la concentración de poder en el Presidente exorbita el cuadro de órganos, en cuanto a la relación teórica de equilibrio. Con todo, debemos reconocer con $\mathrm{G}$. Leibholz que en el proceso de creciente democratización los "derechos de control» han perdido eficacia frente a la conformación de mayorías parlamentarias afines al Gobierno, en particular una «unión de poder, dentro de un monismo parlamentario" (R. Thoma), que hace verbi gratia del Presupuesto una ley del Poder Ejecutivo; también la «democracia de partidos" hace lo suyo en la minusvalía de los "derechos de control" que hace, verbi gratia, del parlamentario un miembro de partido político sometido a un verdadero mandato imperativo. Leibholz sostiene en este punto: "podemos resumir diciendo que la sucesiva democratización, que condujo a la desposesión del poder del antiguo contrincante del Parlamento, así como el cambio estructural de la democracia parlamentaria y representativa a un Estado de Partidos, ha producido una sensible disminución de los derechos de control, primero de los diputados en particular, después de las fracciones politicas y finalmente, de todo el Parlamento" ${ }^{19}$.

Por ello, resulta atingente sostener que los "derechos de control" deban construirse como institutos disponibles por la minoría-oposición parlamentaria, para que adquieran real efectividad. Al respecto $E$. Stein en su "Staatsrechts" plantea que el "problema constitucional más importante del Parlamento consiste en la protección de las minorías. Este órgano no constituye una unidad sociológica, como podría parecer cuando se habla de "el Parlamento". Por lo general, sus derechos pueden ser ejercitados por la mayoría contra la voluntad de la minoría. Pero la mayoría está vinculada íntimamente al Gobierno. Si no se protegiese a la minoría, la mayoría gubernamental podría transformar al Parlamento en Cámaras de resonancia del Gobierno.

Las garantías que protegen a las minorías en el Parlamento están por regla contenidas en los reglamentos internos que proporcionalmente asignan los cargos de órganos de dirección o trabajo en cada Cámara. En cuanto a la función de control y el recaudo de independencia del controlante, su no concurrencia se explica por la conformación de una mayoría "parlamentaria-gubernamental". Para Stein la

19 LeibHOLZ, Gerhard: "Problemas Fundamentales de la Democracia Modernan, Edit. I.E.P., Madrid, 1971, pág. 72.

Idem: E. STEIN: "Derecho Político" (estudio de F. Rubio), Ed. Aguilar, S.A., Madrid, 1973, pág. 53, N. $^{\circ} 73-75$. 
clave del control real de Gobierno y Administración está en que su ejercicio (función-medios) debe corresponder a quienes no participan del ejercicio del poder, a la oposición-minoría. En este contexto Stein, prefiere hablar de "derechos de corrección" y no de derechos de control para el ejercicio de medios referidos al Gobierno, su programa y acción (voto de censura, aprobación del presupuesto), y propiamente habla de "derechos de control» cuando la oposición-minoría, no pretende adoptar decisiones contra el Gobierno, sino cuando se forma opinión pública sobre un asunto de interés público (preguntas orales, petición de información, preguntas escritas, interpelaciones, comisiones de investigación).

En este complejo cuadro emerge la función de control del Parlamento, categoría (control) plurisignificativa en su especie (control parlamentario) y multidimensional, pues el Parlamento es el agente y el locus del control parlamentario.

En la definición del control del parlamentario tenemos al menos dos posiciones doctrinales. V. gr. entender el control como actividad de juicio o verificación (a la que queda subordinada la función cognoscitiva e inspectiva) que incluye la adopción de medidas conducentes a hacer cesar la situación no conforme a valores que se tratan de proteger (Santaolalla) o bien entender el control como la confrontación de una conducta determinada con el parámetro al que debe adecuarse y no importa en sí mismo, medida sancionatoria o reparadora (Montero y García Morillo) ${ }^{20}$.

Ciertamente, en la función de control la última ratio es la responsabilidad (especialmente en regímenes parlamentarios), pero cabría distinguir entre: control-cognición e inspección y control-autorización. La acepción extensiva de control parlamentario, parece más adecuada para dar cuenta del control en el contexto presidencialista y la eficacia de éste en la formación de opinión pública y la responsabilidad política indirecta que ella genera a través de elecciones periódicas. En cambio, la acepción restrictiva de control parlamentario más extendida entre los constitucionalistas lo identifica con la responsabilidad

20 Santaolalla, Fernando: "Derecho Parlamentario Español», Espasa Calpe, S.A., Madrid, 1990, págs. 239-245.

Idem: "El Parlamento y sus instrumentos de información", Edersa, Madrid, 1982.

Montero Gibert, J. R. y Garcia Morillo, J: "El Control Parlamentario", Edit. Tecnos, S.A., Madrid, 1984, págs. 28 y siguientes, págs. 45-61.

Idem: Garcia Morillo: "Aproximación a un concepto de control parlamentario", Revista Facultad de Derecho U.C. N. ${ }^{\circ}$ 10, Madrid, 1986, pág 31-71. 
política del Gobierno (efecto sancionatorio). Por ello me parece acertado lo que sostienen Montero y García Morillo: «así entendido, el control parlamentario integraría dos partes fundamentales: los mecanismos que permiten conocer la labor desarrollada por el Ejecutivo y los instrumentos que contiene la sanción parlamentaria de su remoción de cargo (...). Se trata, como es evidente, de una traslación al campo constitucional del concepto de control jurídico que antes criticábamos por integrar dentro del concepto de control al elemento sancionatorio y por confundir a nuestro juicio, la parte (el control) con el todo (la garantía) dentro de la que se integran control y sanción" ${ }^{21}$.

Por otra parte, una confirmación de la tesis extensiva de control parlamentario esta dado por la multidimensionalidad de éste, es decir, en la realidad de la "democracia de partidos" y de conformación de mayorías parlamentarias, la función de control (en su acepción restrictiva) deviene en una ilusión o espejismo; por lo que me parece acertada la afirmación de Rubio Llorente en orden a que más que función de control del Parlamento deberíamos decir función de control dada en el Parlamento, como locus funcional más que agente real, permitiendo la "publicidad de la política y la de control de la Administración»"2 Rubio Llorente nos recuerda: "en las democracias parlamentarias de nuestro tiempo, en efecto, el control parlamentario es la vía más idónea para hacer llegar a la oposición la información crítica sobre la actuación del Gobierno, sin la cual ninguna democracia es imaginable y para asegurar en lo posible que el poder de la burocracia no se autonomice más de lo que la propia naturaleza de las cosas hace inevitable» (...) "El control directo del Parlamento sobre la Administración responde a una necesidad innegable. El incremento de la intervención estatal en los procesos sociales y económicos ha dado lugar al surgimiento de aparatos administrativos tecnificados y complejos, que aunque sometidos, de manera más o menos directa, a los distintos Departamentos Ministeriales, escapan de hecho al control de los titulares de éstos. Esta necesidad, de la que resulta, como de la disminución del poder efectivo del Parlamento para exigir la responsabilidad política del Gobierno, una notable aproximación entre las distintas formas (parlamentaria, presipág. 209

Montero y García Morillo: Ob. cit., págs. 27 y ss.

Rubıo LloRente, Francisco: "La Forma del Poder», Edit. CEC, Madrid, 1993,

Idem: El agudo politólogo Bernard R. CRICK: "The Reform of Parliament", Weidenfeld, London, 1970, pág. 238.

Idem: Andrea ManzelLA: "Il Parlamento", II Mulino, Bologna, 1" ed., 1977, nueva edición 1991, págs. 135 y ss. 
dencialista, etc.) de la democracia parlamentaria, ha dado lugar a la adopción por los Parlamentos europeos de formas de actuación lespecialmente las comisiones de investigación y seguimiento) nacidas en el Congreso de los Estados Unidos, o la creación de instituciones (p. ej. el Ombudsman) surgidos en regímenes parlamentarios en los que el Gobierno no era políticamente responsable de la actividad de toda la administración $»^{23}$.

En este orden de ideas, en América Latina la constitucionalización del Ombudsman o Defensor del Pueblo y de las comisiones de investigación, dan cuenta de la multidimensionalidad del control parlamentario; aunque la Defensoría no siempre es en propiedad un comisionado parlamentario ${ }^{24}$.

Esta multidimensionalidad y plurisignificación del control parlamentario, permite zafar esta categoría de construcciones teóricas ancladas en el concepto de control jurídico o en formas de Gobierno parlamentario, en que el control reposa en su última ratio: la responsabilidad política (relación fiduciaria Parlamento-Gobierno), y además, permite adecuar tal concepto de control parlamentario en el régimen presidencial y presidencialista.

En efecto en un régimen presidencial de useparación rígida de poderes", la existencia de controles (checks and balances) para un adecuado equilibrio no responde a la idea de que el Parlamento ha de revisar el nivel de adecuación del Presidente a una voluntad política de la que es depositaria la institución parlamentaria como único órgano de representación política. Por el contrario en el régimen presidencial y en los presidencialismos: Presidente y Parlamento son órganos de representación política, dotados de legitimidad democrática directa.

Por lo demás, en la actualidad, en los regímenes parlamentarios el Gobierno crecientemente asume un poder de dirección política (indirizzo), ganando en legitimación democrática directa (sea bajo la forma semi-presidencial, un sistema electoral, recurso al referéndum, entre otros). Con agudeza López Guerra observa que "la presencia de partidos políticos jerarquizados y de sistemas electorales de corte ma-

23 Rubio LloRente, F.: Ob. cit., pág. 210-211.

24 ZúÑiga U., F.: «Defensor del Pueblo». "Reformas Constitucionales Recientes en América Latina". En Libro Homenaje a Tomás Salinas, Edit. U.C., Madrid, 1995.

Idem revistas $\mathrm{N} .{ }^{\circ} 0,1,2,3$, de la Asociación lberoamericana del Ombudsman con artículos monográficos. 
yoritario, en efecto, convierten de hecho a las elecciones parlamentarias no sólo en forma de selección de los representantes en las Asambleas legislativas, sino también un proceso de selección de los líderes del Ejecutivo ...." ${ }^{25}$.

En suma, el control parlamentario es en gran medida el control que pueda ejercer la minoría en el Parlamento y no una mayoría parlamentaria-gubernamental, que ni en un régimen parlamentario ni presidencial permitirá ejercer el control en su última ratio la responsabilidad política directa (que inclusive puede llevar a hacer efectiva la relación fiduciaria en los parlamentarismos).

De esta manera, conceptuado el control parlamentario en su acepción extensiva y determinada su multidimensionalidad, corresponde identificar la función de control y emplear sus medios de cognición e inspección ("derechos de control») con eficiencia; lo que politológicamente supone la existencia de una oposición política. Inclusive más en los presidencialismos, con un grado menor de articulación de partidos y de sistemas de partidos, es posible conformar mayorías ad-hoc, para de tacto hacer efectiva una responsabilidad "política" a través de un medio anómalo: el impeachment o acusación en juicio político, medio necesario que ha dado pruebas recientes de vitalidad en nuestra América, que en otro tiempo y lugar, una crisis de gobierno era resuelta de forma más o menos cruenta a través de la técnica del golpe de Estado o el golpe de mano.

En este punto me parece correcto trasladar, con matizaciones, el enfoque de López Guerra sobre control parlamentario, de otro contexto político-institucional como el español al control parlamentario en un régimen presidencialista: "por tanto, habría que concluir que sí, efectivamente, este control existe es con un objetivo diferente: no para comparar la actuación del Gobierno con una voluntad popular ya manifestada, sino para comparar esa actividad con unos objetivos a seguir en el futuro (y obviamente no conseguidos), al objeto de motivar en elecciones subsiguientes un cambio en la voluntad del electorado. Dicho de otra forma, lo que persigue el control de la minoría es, evidentemente, una extensión de la información de los defectos de la actuación gubernamental en comparación con un desideratum que la oposición representaría. Ello supone llegar quizá a un Mediterráneo ya descu-

25 López Guerra, Luis: "La Función de Control de los Parlamentos: Problemas Actuales». En "El Parlamento y sus transformaciones Actuales", Edit. Tecnos, S.A., Madrid, 1990, pág. 239. 
bierto, el de que la función de control representa, sobre todo, una función de información y que es en la difusión informativa donde reside la efectiva capacidad controladora del Parlamento, o para ser más exactos, de la minoría en la oposición ${ }^{26}$. Se producirá asi una convergencia europeo-americana del Parlamento, en el sentido que la labor de control no se basa tanto en la superioridad (soberania) del Parlamento, sino en la capacidad de éste de allegar mayor información y generar encuestas o investigaciones relativas al Gobierno y la Administración.

La definición dada de control parlamentario y su multidimensionalidad une al control sus medios de cognición e inspección, aunque creemos que los medios (preguntas, interpelaciones, comisiones de encuesta, entre otros) se configuran como una función específica del Parlamento: cognoscitiva e inspectiva, aunque subordinada en lo instrumental a la función de control.

\section{CONTROL PARLAMENTARIO Y SUS MEDIOS ANTE LA NECESIDAD DE UNA REFORMA CONSTITUCIONAL}

En términos axiomáticos el Estado de Derecho exige que todo poder esté sometido a control, axioma que tiene concreción en controles horizontales, verticales, intra e inter órganos, cuyo maximun es hoy en intensidad el control de constitucionalidad de la ley. En cuanto al control parlamentario como control horizontal e interórgano está referido al Gobierno y Administración, conceptos funcionales y orgánicos, que en nuestro contexto quedan englobados en la institución presidencial. En último término el control puede llegar a ser "antesala y presupuesto de la responsabilidad" (Vanossi) ${ }^{27}$, sea esta responsabilidad directa o indirecta, normal u anormal, como sucede con el «impeachment»; campos en que la minoría-oposición tiene un rol de primer orden; pero de ordinario el control parlamentario se ejerce $y$ confunde con sus medios de cognición e inspección.

En el caso de Chile la Constitución estatal de 1980, reformada en diversas ocasiones (1989, 1991, 1994, 1996 y 1997) contiene "enclaves" autoritarios que paulatinamente en la transición política han sido re-

\footnotetext{
26 López Guerra: Ob. cit., pág. 246.

27 VANOSSI, J. R. A.: "El Estado de Derecho en el Constitucionalismo Social", Eudeba, Buenos Aires, 1987, pág. 94.

Idem Pierre AvriL: "Pouvoir et responsabilité". En "Le Pouvoir Mélanges offerts a Georges Burdeau", L.G.D.J., París, 1977, págs. 9 y ss.
} 
movidos. Un proyecto de Reforma Constitucional (hoy fallido) abordó entre otras materias la modificación sustantiva del artículo $48, N .^{\circ} 1$ de la Carta que instituye la "potestad fiscalizadora" de la Cámara de Diputados introduciendo como nuevos medios de cognición e inspección: las interpelaciones y comisiones de investigación, asegurando a una minoría cualificada al ejercicio de estos "derechos de control».

En esta ocasión nos referiremos a las comisiones de investigación como medios o instrumentos de la función cognoscitiva-inspectiva del Parlamento que permite un control más eficiente. Demás está reiterar que con un Parlamento "racionalizado" carente de toda centralidad como el de Chile, una reforma orientada a fortalecer las funciones de la Cámara de Diputados (y democratizar el Senado, por la vía de suprimir las categorías de senadores por derecho propio y designados), encauza el régimen político a una efectiva democracia representativa (forma de Estado) y a un tipo de Gobierno presidencialista "autónomo de equilibrio de poderes" (Colomer Viadel).

Los medios de la función cognoscitiva e inspectiva del Parlamento permiten allegar "información exhaustiva" para el ejercicio de otras funciones y si está encaminada a verificar la correspondencia de la actividad de Gobierno y Administración con orientaciones parlamentarias cae dentro de la función inspectiva (G. De Vergottini). La función cognoscitiva e inspectiva queda así por sus medios frecuentemente subordinada al control parlamentario y a las valoraciones político-programáticas de la minoria-oposición.

En cuanto a las comisiones de encuesta o investigación éstas pueden ser comisiones permanentes (Standing Committess en caso norteamericano) o comisiones temporales, creadas por el órgano interno rector de la Cámara, con una competencia delimitada que comprende incluso atribuciones parajudiciales. El Derecho Constitucional Comparado nos da muestras notables de comisiones de encuesta o investigación (Constitución belga de 1831, art. 40; Constitución italiana de 1948, art. 82; Ley Fundamental alemana de 1949, art. 44; Constitución japonesa de 1946, art. 62; Constitución griega de 1975, art. 68; Constitución portuguesa de 1976, art. 181; Constitución española de 1978, art. 76).

Para efectos de comparación quisiera detenerme en el caso español, con un régimen diverso al de Chile, para establecer semejanzas, diferencias y problemas de la comisión temporal de encuesta. Al respecto, F. Fernández Segado define las comisiones de investigación como "órganos colegiados de control de carácter no permanente que pueden constituirse en el seno del Congreso, del Senado o de ambas 
Cámaras conjuntamente con vistas al estudio o investigación sobre cualquier asunto de interés público» ${ }^{28}$. La formación de una comisión de investigación requiere en el Congreso de los Diputados un acuerdo del pleno de la Cámara, a propuesta del Gobierno, la Mesa, de dos Grupos Parlamentarios o de la quinta parte de sus miembros (Capítulo III De las Comisiones, Sección III De las Comisiones no permanentes, arts. 51-53 de Reglamento de C.D., de 1982). En el Senado la comisión de investigación es establecida por el Pleno de la Cámara, a propuesta del Gobierno o de veinticinco senadores que no pertenezcan al mismo Grupo Parlamentario (Capítulo IV De las Comisiones, Sección IV Comisiones de investigación o especiales, artículos 59-60 del Reglamento del Senado, de 1982).

Una de las importantes atribuciones de las comisiones de investigación en el caso español es la facultad de requerir la presencia ante ellas de cualquier persona para que pueda ser oída, requerimiento que deberá hacerse por conducto de la Presidencia de la Cámara, comunicando con una antelación de 3 días los extremos sobre los que haya de informar. Tal comparencia obligatoria ante comisiones de investigación está regulada en Ley orgánica $5 / 1984,24$ de mayo (art. $1 .^{\circ}, 2 .^{\circ}, 3 .^{\circ}, 4 .^{\circ}$ y $5 . \%$. Con todo, en el marco de la función cognoscitiva e inspectiva, López Aguilar destaca que al tenor de los arts. 44 y 51 de R. C.D. las comisiones permanentes y no permanentes tienen la posibilidad de recabar "la presencia ante ellas de personalidades cuyos testimonios puedan revestir un interés objetivo, aun cuando no se trate ni de autoridades ni de funcionarios públicos ${ }^{29}$. Sobre las comisiones de investigación cabe recoger dos observaciones críticas gruesas: dialéctica minoría-mayoría y eficacia inspectiva-controladora de los órganos de encuesta.

En un primer sentido crítico las comisiones de investigación no están al alcance efectivo de la propia minoría (López Aguilar, Fernández Segado); dado que sus facultades extraordinarias tropiezan con el límite objetivo de la conformidad y respaldo que presten las mayorías a todas las actuaciones de la Administración -presumiendo, por principio, su regularidad-así como que, por último, opere preceptivamente

28 Férnandez Segado, Francisco: "El Sistema Constitucional Español», Edit. Dykinson, Madrid, 1992, pág. 655.

Idem: López GuerRa L., Garcia Morillo J. y otros: "Derecho Constitucional» (2 vol.), Edit. Tirant lo blanch, Valencia, 1994, Vol. II, págs. 124-125.

29 López Agullar, Juan Fernando: "Oposición Parlamentaria y el Orden Constitucionalı, Edit. CEC, Madrid, 1988, pág. 282. 
la regla del secreto (arts. 64.3 y 75 R.S.), en el desenvolvimiento de la totalidad de las actividades de las comisiones de encuesta; que por su poder inquisitivo sobre la regularidad de los asuntos públicos no haya despertado al menos hasta la fecha, "confianza alguna dada la gran variedad de recursos con que cuenta el aparato administrativo del Estado para resistir o desviar la atención respecto a aquellos hechos objeto de demandas de fiscalización parlamentaria...." ${ }^{30}$.

En un segundo sentido crítico a la eficacia inspectiva-controladora de las comisiones de investigación, P. Lucas Murillo destaca que "a la vista de la experiencia española de los últimos años, se puede decir, todo menos que estas comisiones hayan supuesto riesgo alguno. Al contrario, su actuación ha sido en general más bien anodina y en ocasiones se han revelado como una adecuada válvula de escape, que ha permitido al Gobierno y a la mayoría parlamentaria salir del paso trasladando un tema polémico o una cuestión comprometida al sosiego -secreto en algunos casos- de las comisiones de investigación. Así, éstas han servido para congelar temas conflictivos en los que los grupos mayoritarios no tenían demasiado interés en entrar a fondo» ${ }^{31}$. Un elemento adicional a destacar es que junto a la convergencia que se produce en la caracterización del Parlamento en los regímenes-tipos de gobierno parlamentario-presidencial, también las Comisiones y secciones producto de una evolución histórica, se asientan como órganos de control, en evidente convergencia con las comisiones del Congreso Norteamericano (J. Jiménez Campo), aunque se reconoce que las comisiones de investigación son instrumentos de la mayoría, lo que degrada su "operatividad real como medio de fiscalización de la gestión gubernamental». En suma, del reconocimiento de la doble condición del Parlamento: orgánica e institucional, es fuerza reconocer que como complejo de órganos su actuación se verifica a través del principio mayoritario, pero tratándose de la relevancia institucional del Parlamento

30 López Aguilar, J. F.: Ob. cit., págs. 286-287.

31 Lucas Murillo de la Cueva, Pablo: "Las Comisiones de Investigación en las Cortes». En Revista Facultad de Derecho de la Universidad Complutense, N. ${ }^{\circ} 10$, 1986, págs. 143-173, págs. 170-171.

Idem: Arévalo Gutierrez, Alonso: "Las Comisiones de Investigación de las Cortes Generales y de las Asambleas Legislativas de las Comunidades Autónomas", Revista Española de Derecho Constitucional, N. ${ }^{\circ} 43$, Madrid, CEC, 1995, págs. 113-205.

Idem: Javier JimÉnez CAMPo: "Sobre el Control Parlamentario en Comisión". En "Estudios en homenaje a Francisco Murillo Ferrol» (2 vol.), Ed. CEC-CIS, Madrid, 1987, Vol. l, págs. 477-492. 
la función de control en cuanto expresión del pluralismo social debe quedar encomendada a la minoría-oposición (Stein, Crick, Rubio Llorente, Jiménez Campo).

Para cerrar este punto cabe retornar al fallido proyecto de Reforma Constitucional de Chile, que en el apartado específico proponía modificar el art. $48 \mathrm{~N} .^{\circ} 1$ de la Carta Política en el sentido siguiente:

Artículo $4 .^{\circ}$. Sustitúyese el número 1 del artículo 48 de la Constitución Política de la República, por el siguiente:

"1. Fiscalizar los actos del Gobierno. Para ejercer esta atribución la Cámara puede, con el voto de la mayoría de los Diputados presentes, adoptar acuerdos o sugerir observaciones, las que se transmitirán por escrito al Presidente de la República, debiendo el Gobierno dar respuesta, por medio del Ministro de Estado que corresponda, dentro de treinta días. En ningún caso los acuerdos u observaciones afectarán la responsabilidad política de los Ministros, y la obligación del Gobierno se entenderá cumplida por el sólo hecho de entregar su respuesta.

Sin perjuicio de lo anterior, cualquier Diputado con el voto favorable de a lo menos un tercio de los miembros presentes de la Cámara, podrá solicitar determinados antecedentes al Gobierno. El Gobierno deberá dar respuesta, por medio del Ministro que corresponda, dentro del mismo plazo señalado en el inciso anterior.

Para ejercer la atribución a que se refiere el inciso primero de este número, la Cámara puede citar a un Ministro de Estado, a petición de a lo menos dos quintos de los diputados en ejercicio, a fin de formularle consultas especificas sobre materias vinculadas al ejercicio de su cargo. Con todo, un mismo Ministro no podrá ser citado más de dos veces dentro de un año calendario y nunca sin que haya trascurrido seis meses de la última citación.

Lo anterior es sin perjucio del derecho que confiere a los Ministros de Estado el articulo 37.

El presidente de la Cámara determinará la sesión a la que deberá concurrir el Ministro respectivo, la que deberá tener lugar no antes de los siete días siguientes a aquél en que se acordó su citación. La asistencia del Ministro será obligatoria y deberá responder a las consultas que motiven su citación, así como las que se planteen durante la sesión y que estén directamente vinculadas con la materia objeto de la citación. El Ministro podrá concurrir a la respectiva sesión acompañado de sus asesores. 
Para los efectos de adoptar los acuerdos u observaciones a que se refiere el inciso primero de este número, la Cámara podrá crear comisiones investigadoras a petición de a lo menos dos quintos de los diputados en ejercicio. Los funcionarios de los órganos de la Administración del Estado, incluyendo los de las empresas creadas por ley, estarán obligados a comparecer y a entregar los antecedentes que éstas le soliciten.

La ley orgánica constitucional del Congreso Nacional determinará las atribuciones y funcionamiento de estas comisiones y las sanciones en caso de no comparencia, debiendo, en todo caso, contemplar las garantias $y$ resguardos que aseguren el respeto de los derechos de las personas que resulten afectadas por la investigación en alguna forma.

Las conclusiones de la investigación, una vez aprobadas por la Cámara, y así lo resuelve la Sala, deberán ser puestas en conocimiento del Gobierno, de los Tribunales de Justicia, de la Contraloría General de la República, o de los órganos que estime conveniente".

A modo de conclusión, el ejercicio téorico (Derecho Constitucional General) y comparativo (Derecho Constitucional Comparado) sobre la función de control del Parlamento y sus medios cognoscitivos e inspectivos, en particular de las comisiones investigadoras, nos permiten formular un conjunto de comentarios críticos respecto del instituto incorporado al fallido proyecto de Reforma Constitucional, a saber:

a) Un concepto de control parlamentario en el marco de una acepción extensiva que distingue el control mismo de su garantía, otorga la flexibilidad necesaria para que esta categoría opere en cualquier régimen político-tipo de gobierno democrático con independencia de la relación fiduciaria y de la responsabilidad política directa.

b) En el modelo clásico de régimen presidencial el control parlamentario aparece fortalecido por la inserción institucional de comisiones permanentes de las Cámaras en la toma de decisiones políticas, todo sin perjuicio del sistema bipartidista.

c) El control parlamentario es plurisignificativo y multidimensional, lo que unido a su flexibilidad y necesidad como categoría iuspolítica; permite hacer efectiva responsabilidades políticas directas (parlamentarismo) o indirectas (presidencialismo), en especial contribuir a formar opinión pública.

d) Los medios rogatorios (preguntas, interpelaciones) e inspectivos (comisiones de encuesta) imbricados en una función cognoscitiva e inspectiva frecuentemente son medios apropiados para el control parlamentario. 
e) El control parlamentario tiene presupuestos o recaudos: independencia del controlante del controlado, determinación de un ámbito de control y derecho de información y publicidad de los actos (Vanossi) $^{32}$. La independencia del controlante es asegurada por el principio de separación de poderes y el pluralismo político. La determinación de un ámbito de control (actos del Gobierno que engloba actos de Gobierno y actos de la Administración) le confiere especial entidad al control político; sin perjuicio del ensanche de la justiciabilidad de los actos de la Administración y actos políticos. El derecho de información y publicidad de los actos de poder, que designa la repulsa a los arcana imperii, es una de las claves en la formación de opinión pública.

f) En la sistemática de nuestro Derecho Parlamentario las Comisiones Investigadoras, son tratadas en el Reglamento de la Cámara de Diputados (Libro Tercero, título III), en el marco de la función cognoscitiva-inspectiva y con la acusación constitucional. Las Comisiones Investigadoras son un tipo de comisiones de la Cámara (art. 212) y se rigen por las reglas especiales referidas; y tendrán la competencia fijada en los acuerdos de la Cámara que decidan su constitución, competencia para desarrollar la investigación que se extingue al vencimiento del plazo fijado por la Cámara para el cumplimiento de su cometido el que puede ser ampliado o renovado por la Sala con el quórum ordinario.

Las Comisiones Investigadoras tienen facultades "parajudiciales", ya que podrán citar Ministros de Estado, funcionarios de la administración del Estado, de personas jurídicas de derecho público, empresas del Estado e incluso particulares. Los citados a Comisiones Investigadoras, podrán asistir acompañados de un asesor. El informe de las Comisiones Investigadoras deberá ser suscrito por un número de Diputados equivalente al quórum que requirió de la Comisión para adoptar acuerdos y también por el Secretario de la Comisión. Una copia del informe aprobado por la Cámara deberá remitirse al Presidente de la República. Finalmente el Reglamento camaral establece un privilegio para Diputados en orden a reservar sus fuentes de información, pudiendo rehusar, prestar testimonios sobre esta materia.

Las referidas Comisiones Investigadoras en cuanto órganos internos de la Cámara de Diputados, cumplen un rol instrumental a la función de control político-parlamentario, la que se instrumenta a tra-

32 Vanossi, J. R. A.: "Democracia Constitucional: Pluralismo y Control». En "El Control Parlamentario del Gobierno en las Democracias Pluralistas", Ed. por M. Ramirez, Edit. Labor, S.A., Barcelona, 1978, págs. 17-44. 
vés de "acuerdos" y "oficios fiscalizadores"; según lo previsto en el N. ${ }^{\circ} 1$ del art. 48 de la Constitución; por lo que estas Comisiones no ejercen en sí mismas un función de control, la que corresponde a la Cámara de Diputados como órgano plenario (Sala), sino una función cognoscitiva-inspectiva por regla subordinada al control político-parlamentario.

Las comisiones de investigación o encuesta en cuanto medios inspectivos son órganos temporales de las Cámaras (en el presidencialismo de Chile es propio de la Cámara de Diputados, estándole vedado el control político al Senado en virtud de lo dispuesto en art. 48, $N^{\circ} 1$ y art. 49 inciso final de la Constitución), que para una adecuada racionalización requieren de ciertos recaudos, a saber:

* Permitir a una minoría cualificada constituir el quórum aprobatorio de formación de una comisión de encuesta.

* El ámbito de competencia definido en el acuerdo aprobatorio de formación de la Comisión de investigación, debe especificarse por dicha minoría cualificada.

* El informe final, tanto de mayoría como de minoría deben gozar de adecuada publicidad.

* La comisión de encuesta debe estar revestida de la facultad, de ordenar comparecencia obligatoria de funcionarios y demás personas concernidas en la investigación; personas que deben ser resguardadas en sus derechos fundamentales, sin que ello importe abusar del secreto de actas de comisión.

* Las garantías de los derechos fundamentales de las personas concernidas en la investigación o encuesta, deben estar reguladas en ley en sentido formal.

* La comisión de encuesta debe estar revestida de facultades parajudiciales. V. gr. potestad de imperio y legitimación activa para incoar a órganos jurisdictores o de control jurídico.

* Los recaudos básicos del instituto de la comisión de investigación para una adecuada racionalización deben ser incorporados a la Carta Política; reservando su complejo regulatorio a la potestad de autonormación reglamentaria de la Cámara de Diputados, con la única excepción de la regulación de las garantías en ley en sentido formal.

g) La centralidad del Parlamento esta ligada a las nociones de control parlamentario eficaz y de dirección política (“indirizzo»). En regímenes presidencialistas la eficacia de los medios de cognición e ins- 
pección, están unidos a un dato fáctico: la configuración del sistema de partidos y mecanismos de formación de opinión pública. En el modelo clásico de régimen presidencial los Standing Committes e Investigating Committess, son órganos especializados, permanentes $y$ temporales respectivamente, de gran fortaleza (sin que sustituyan a los órganos plenarios de decisión) y que gozan de importante prestigio en la opinión pública. Ciertamente no ocurre lo mismo con nuestras autóctonas comisiones de investigación.

En este contexto resulta imperiosa una Reforma Constitucional que aborde los temas de centralidad y funcionalidad del Congreso Nacional, y que instituya instrumentos de cognición e inspección de la Cámara de Diputados en relación a los actos del Gobierno, como son las interpelaciones tratadas en otro lugar, y las comisiones de investigación.

\section{CONCLUSIONES}

El estudio del Parlamento y el control político, y los medios de cognición e inspección acometidos en este trabajo, exigen el uso de un esquema teórico-práctico, que adecuado a las realidades de cada régimen político y tipo de gobierno, den cuenta de la imperiosa centralidad de la institución parlamentaria en el Estado democrático, superando esquemas modélicos añejos y lastres ideológicos, que en el fondo trasuntan desconfianza o repulsa de la democracia como forma de Estado.

A nuestro juicio la mentada crisis del Parlamento, en ocasiones ideada sobre bases modélicas y fines ideológicos como lo hace $\mathrm{C}$. Schmitt, no es sino la transformación de la institución liberal burguesa decimonónica (anclada en el dogma de la soberanía parlamentaria y de la representación política) dedicada a vigilar al Poder Ejecutivo para proteger la libertad y la propiedad (en especial en contextos monárquico constitucionales), para lo cual estaba dotada de funciones e instrumentos apropiado a sus fines. Pero una vez superada la «coincidencia» liberalismo-democracia en el Estado Benefactor o tardocapitalista, las funciones e instrumentos del Parlamento cambian en sus centros de gravedad y orientaciones.

En el contexto del Estado Administrativo, de la democracia de partidos, de la representación de intereses, entre otros fenómenos, más que un desplazamiento del Parlamento se ha consolidado una verdadera "poliarquía" en que sobresale como un sistema cerrado la Burocracia, transfomándose la Administración en el objeto preferente de la realzada función de control parlamentario. 
Precisamente referimos a la centralidad del Parlamento significa aludir al control parlamentario en especial del Gobierno-Administración, para que el Poder Ejecutivo fuerte no sea incontrolado y se conserve el Estado de Derecho como forma jurídico-política de la democracia representativa. De esta manera, la valoración positiva de instrumentos de cognición e inspección, en especial de la comisión de investigación no es un ejercicio de «ingeniería constitucional» (Sartori) ${ }^{33}$, para restaurar una centralidad perdida de la institución parlamentaria, sino la valorización de un medio o instrumento que integrando la función cognoscitiva e inspectiva pemite hacer efectivo el control parlamentario en su plurisignificación y multidimensionalidad.

En este orden de ideas, P. Lucas Verdú reivindica las categorías de la doctrina italiana de "centralidad" y "funcionalidad" del Parlamento, como diversas de las añejas omnipotencia y soberanía parlamentaria, insertas en una organización estatal en que los órganos están dotados de diversos controles, y en último témino los propios derechos fundamentales importan límites negativos y positivos del poder. La centralidad de la institución parlamentaria descansaría en cuatro elementos interdependientes: «a) recuperación de la posición estratégica que debe corresponder al Parlamento en el sistema político-constitucional; b) conquista de la capacidad para cumplir las grandes decisiones y dictar sus correspondientes orientaciones; $c$ ) hallar un punto que interrelacione el sistema de órganos representativos y los diversos sujetos institucionales existentes en el pais; d) Identificar el Parlamento como lugar de respuesta inmediata a las demandas que provienen de la sociedad"... y la funcionalidad esta referida a la pluralidad de centros funcionales del Parlamento que exceden la relación fiduciaria.

Hemos demostrado que el control político, jurídico y social del poder es un elemento básico del poder estatal en un Estado de Derecho. Sin embargo en sí mismo el término control tiene acepciones diversas en lengua inglesa y francesa, en la primera implica dominiosupremacía (Sánchez Agesta, Torres del Moral) y en la segunda comprobación, examen, inspección, registro y revisión. Las acepciones singularizadas tienen una estrecha relación con el tipo de gobierno y régimen político, por lo que un típico control político, como el control

33 Lucas Verdú, Pablo: “Curso de Derecho Político». Vol. IV, Edit. Tecnos, S.A., Madrid, 1984, págs. 612-657.

Sobre ingeniena constitucional consultar a Giovanni SARTORI: "Ingeniería Constitucional Comparadan, F.C.E., México D.F., 1994, págs. 211 -218. 
parlamentario, puede operar en regímenes parlamentarios, presidenciales, semipresidenciales, presidencialistas y directoriales, pero su alcance en el campo de la responsabilidad política difiere en la teoría y en la práctica. No cabe duda que disociado el control político-parlamentario de la responsabilidad política, tal disociación se produce tanto en los regímenes parlamentarios como presidenciales, tratados éstos como tipos polares, sea por la lógica del Estado de partidos (mayoría parlamentaria-gubernamental) o por la lógica del régimen presidencial, en el que no cabe la relación fiduciaria Gobierno-parlamento. En suma, tenemos una paradoja, consistente en que el control parlamentario, con independencia del régimen político tiene por objetivo una lejana responsabilidad política indirecta o "difusa" (Torres del Moral). En este orden de ideas la función de control y sus medios, si bien recae sobre el Gobierno, examina la actuación de éste para comprobar "si se ajusta o no a lo que el Parlamento considera correcto"; por lo que es la publicidad y crítica de los actos del Gobierno la piedra de toque del verdadero control Parlamentario, que hace posible la responsabilidad política "difusa", que no destituye al Gobierno pero sí comporta su "desgaste político" ${ }^{34}$. En el fondo la racionalización del Parlamento se extiende, también, al control Parlamentario y a la responsabilidad del Gobierno, como correctivo a la inestabilidad; observándose por Grewe y Ruiz Fabri una "declinación del control con sanción" $\vee$ una "preponderancia del control sin sanción»; ya que el objetivo hoy del control es asegurar la debida publicidad de la acción gubernamental y la critica a ésta por la oposición; generándose un fenómeno de "circulación de la información»" ${ }^{35}$.

La conclusión resulta obvia: la función legislativa racionalizada en el Parlamento moderno, por el fenómeno del Estado de partidos o por la fortaleza de la institución presidencial, encuentra en el control parlamentario un verdadero contrapeso (A. Manzella); por lo que resulta imperioso en un régimen presidencialista como el nuestro forta-

34 Torres del Moral, Antonio: "Estado de Derecho y ...", págs. 453 y ss. y págs. 484 y ss.

Idem: del mismo autor "Principios de Derechos Constitucional Español", Servicio de Publicaciones de la Facultad de Derecho, Universidad Complutense, $3^{\mathrm{a}}$ edic., Madrid, 1992, págs. 191 y ss.

Idem: sobre el Estado de partidos un brillante tratamiento politológico encontramos en Klaus von Beyme: "La Clase Política en el Estado de partidos", Atianza Editorial, S.A., Madrid, 1995.

35 Grewe, Constante y Ruiz Fabri, Héléne: «Droits Constitutionnels européens", PUF, $1^{\text {a }}$ edit., París, 1995, págs. 550 y ss. 
lecer los instrumentos de cognición e inspección de la Cámara de Diputados. Luego, el estudio de las Comisiones Investigadoras son un verdadero pretexto, lo mismo que las interpelaciones, en favor de la centralidad y funcionalidad de nuestro Congreso.

Ciertamente estas categorías están construidas a partir de un tipo de Gobierno parlamentario, pero como aporte itálico poseen la plasticidad para designar que la centralidad-funcionalidad más que una cuestión de "poderes formales" es una primacía de posición del Parlamento (Manzella). Con ello retomamos a nuestra primera idea: la forma de Estado democrático-representativa sólo puede ser construida teórico-prácticamente a partir del principio dogma de la división de poderes y del Parlamento como institución con fines de representación política, integración y legítimación del sistema político. 